\title{
Cardiovascular and metabolic effects of CPAP in obese males with OSA
}

\author{
S.R. Coughlin, L. Mawdsley, J.A. Mugarza, J.P.H. Wilding and P.M.A. Calverley
}

ABSTRACT: Obstructive sleep apnoea is associated with increased blood pressure and other features of the metabolic syndrome. The aim of the present study was to determine the relative effectiveness of continuous positive airway pressure (CPAP) in modifying these outcomes.

A randomised placebo-controlled blinded crossover trial comparing cardiovascular and metabolic outcomes after 6 weeks of therapeutic and sham CPAP was performed in 34 CPAPnaïve patients (mean \pm SD body mass and respiratory disturbance indices were $36.1 \pm 7.6$ and $39.7 \pm 13.8$, respectively).

Mean waking systolic and diastolic blood pressure fell by 6.7 and $4.9 \mathrm{mmHg}$, respectively, when compared with sham CPAP. No change was observed in glucose, lipids, insulin resistance or the proportion of patients with metabolic syndrome. In CPAP-compliant patients the fall in blood pressure was greater and the baroreceptor sensitivity improved significantly but no metabolic variable changed.

In obese Caucasians with untreated obstructive sleep apnoea, continuous positive airways pressure can improve baroreceptor responsiveness and reduce waking blood pressure within 6 weeks, but this treatment period was insufficient to modify insulin resistance or change the metabolic profile. The mechanisms underlying this difference in the time course of blood pressure and metabolic response to continuous positive airway pressure in obstructive sleep apnoea requires further exploration.

KEYWORDS: Baroreceptor sensitivity, blood pressure, insulin resistance, metabolic syndrome, obstructive sleep apnoea

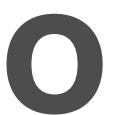
bstructive sleep apnoea (OSA) is a highly prevalent disorder [1] initially identified due to its association with snoring and daytime somnolence [2], but nowadays recognised as being associated with an increased cardiovascular morbidity [3] and, particularly, arterial hypertension [4]. Although initially dismissed as a chance association, a powerful epidemiological case based on controlling for other covariates of hypertension has established that OSA is an independent risk factor for this condition [5]. Similar problems have affected the interpretation of data about insulin resistance (IR), with early studies suggesting this was an epiphenomenon [6]. However, later studies in a variety of patient populations reported an independent effect of OSA on this variable [7-9], with evidence of decreasing insulin sensitivity as the severity of sleep apnoea increases [10]. The composite end-point of raised systemic blood pressure, fasting glucose and lipids, now defined as the metabolic syndrome [11] and itself related to the presence of IR, is significantly more prevalent in OSA sufferers naïve to continuous positive airway pressure (CPAP) treatment than in age- and weight-matched controls [12].

CPAP treatment abolishes the principal physiological abnormality in OSA, i.e. repetitive upper airway obstruction during sleep, reducing daytime sleepiness and improving health status in randomised placebo-controlled trials $[13,14]$. The normal nocturnal fall in arterial blood pressure is reduced or absent in OSA and this can be restored by CPAP therapy, which also reduces waking blood pressure $[15,16]$. Data about the effect of CPAP on the metabolic abnormalities are less robust, since, to date, studies have been uncontrolled and not all report whether body composition, an important determinant of metabolic outcome, changed during the trial period. Nonetheless, improvement in IR assessed by the insulin-clamp technique [17] has been observed, although in the latter study this effect was more evident in less obese patients.

To date, no study has investigated the relative time courses of the response to CPAP treatment and their impact on the number of individuals
AFFILIATIONS

School of Clinical Sciences, University of Liverpool, Liverpool, UK.

CORRESPONDENCE

P.M.A. Calverley

Pulmonary and Rehabilitation Research Group

School of Clinical Sciences

Clinical Sciences Centre

University Hospital Aintree

Lower Lane

Liverpool

L9 7AL

UK

Fax: 441515295888

E-mail: pmacal@liv.ac.uk

Received:

March 282006

Accepted after revision:

December 282006

STATEMENT OF INTEREST

None declared.

European Respiratory Journal

Print ISSN 0903-1936

Online ISSN 1399-3003 
classified as having the metabolic syndrome. The present authors used the opportunity afforded by a delay in the funding of treatment in their area to conduct a prospective randomised crossover study of the effect of CPAP on the metabolic syndrome and its components. In order to confirm the physiological significance of any change in waking blood pressure or glucose, baroreceptor sensitivity (BRS) and IR were also measured. Finally, any change in these variables with CPAP to the degree of CPAP compliance and body habitus was reported.

\section{METHODS \\ Subjects}

The present authors studied untreated patients with a confirmed diagnosis of OSA recruited from the Sleep Disordered Breathing Clinic at the University Hospital Aintree (Liverpool, UK). Subjects were eligible if they were naïve to CPAP, not known to suffer from other medical conditions and were not receiving medication. If any abnormality was identified on a baseline ECG, or there was evidence of diabetes (fasting blood glucose $\geqslant 7.1 \mathrm{mmol} \cdot \mathrm{L}^{-1}$ ), renal, liver or cardiac disease they were excluded, as were patients with symptoms of peripheral neuropathy or a waking diastolic and systolic blood pressure $\geqslant 110$ and $\geqslant 180 \mathrm{mmHg}$, respectively, a level of blood pressure which the present authors felt mandated treatment even if it had not yet begun. Patients with evidence of impaired fasting glucose, impaired glucose tolerance and dyslipidaemia in the absence of diabetes were not excluded. The study complied with the declaration of Helsinki and was approved by the local research ethics committee. All subjects gave informed written consent.

\section{Sleep diagnostic assessment}

All subjects with OSA snored and reported excessive daytime sleepiness or two or more other features typical of the condition, which included impaired concentration, unrefreshing sleep, choking episodes during sleep, witnessed apnoeas, restless sleep, irritability/personality change, nocturia and decreased libido. Excessive daytime sleepiness was assessed using the Epworth Sleepiness Scale (ESS), with a score $\geqslant 10$ indicating a positive result [18]. Diagnosis was confirmed by overnight polysomnography (SleepLab 1000p system; Jaeger, Hoechlberg, Germany) using a standard montage of EEG, electrooculogram and electromyogram signals together with pulse oximetry, respiratory impedance and nasal airflow detected using thermistors. These studies were manually analysed by two technicians using computer software. Apnoea was defined as a cessation of airflow for $\geqslant 10 \mathrm{~s}$ accompanied by $a \geqslant 4 \%$ desaturation in the preceding $30 \mathrm{~s}$. Hypopnoea was defined as a $50 \%$ reduction in airflow accompanied by a $\geqslant 4 \%$ desaturation and a reduction in chest wall movement. EEG arousals were not required to make the diagnosis of a respiratory event. Data were expressed as the respiratory disturbance index based on the mean number of apnoeas and hypopnoeas per hour slept, with an apnoea/ hypopnoea index $>15$ events $\cdot h^{-1}$ confirming a positive diagnosis [19].

\section{CPAP titration}

CPAP titration was performed in the sleep laboratory using the Autoset $^{\mathrm{TM}}$ self-adjusting CPAP device (ResMed Autoscan,
Sydney, Australia) [20]. Data were analysed by two experienced technicians using customised software. Optimal CPAP pressure used in the active limb of the study was defined as the pressure that abolished all apnoeas and the patient's snoring.

\section{Protocol}

After polysomnography and CPAP titration, subjects attended for baseline measurements of body composition and cardiovascular and metabolic variables related to the metabolic syndrome. They were then randomised to receive either therapeutic or identical sham CPAP (Aria LX; Respironics Inc., Pittsburgh, PA, USA), modified as previously described [21], for 6 weeks with CPAP pressure in the sham limb $<1 \mathrm{cmH}_{2} \mathrm{O}$. Machine pressures were confirmed using an electronic manometer. Subjects were told the sham treatment was a low-pressure alternative that might provide some symptomatic benefit. After reassessment, treatment was crossed-over with a final assessment 6 weeks later (fig. 1). Randomisation used a computer-generated sequence of random numbers and CPAP was provided by a technician unconnected with the study, so that both subject and investigators were blinded to treatment allocation. Standard advice and CPAP support was offered throughout the study. Compliance was measured electronically using a smartcard (Encore Pro ${ }^{\circledR}$; Respironics Inc.). Data recorded on the smartcard was related to machine running time, as opposed to the time the mask was at pressure, due to the inability to detect subtherapeutic pressures in the mask. Adequate compliance was prospectively defined as a run time of $\geqslant 3.5 \mathrm{~h} \cdot$ night $^{-1}$ [22].

\section{Body composition}

Weight and percentage body fat were assessed using Tanita TBF-521 bioimpedance scales (Tanita Corp, Tokyo, Japan), and height was recorded. This method had previously been validated against a four-compartment model and was comparable to other prediction techniques, including conventional tetra-polar impedance, skin-fold thickness and body mass index (BMI)-based formulas [23]. BMI $\left(\mathrm{kg} \cdot \mathrm{m}^{-2}\right)$ was calculated as weight divided by height to the power of two. Neck circumference was measured at the level of the laryngeal prominence. Waist circumference was measured midway between the lower rib and iliac crest.

\section{Cardiovascular variables}

Waking blood pressure was measured between 08:00 and 11:00 $\mathrm{h}$ in the supine position after a 5-min rest and recorded as the mean of three measurements taken at 1-min intervals, according to the British Hypertension Society guidelines. An Omron automatic oscillometric digital blood pressure monitor (HEM-705CP; Omron Corporation, Tokyo, Japan) was used. Hypertension was defined, according to the British Hypertension Society guidelines, as a resting systolic and diastolic blood pressure of 140 and $90 \mathrm{mmHg}$, respectively.

BRS was measured under controlled environmental conditions using continuous blood pressure. ECG data were recorded with a Portapres Model II and three ECG limb leads (MP100 ECG acquisition module; BIOPAC Systems Inc., Santa Barbara, CA, USA). Breathing was standardised to 12 breaths $\cdot \mathrm{min}^{-1}$ using auditory command software and confirmed using a Pneumotrace respiration transducer (World Precision) Instruments Ltd, 


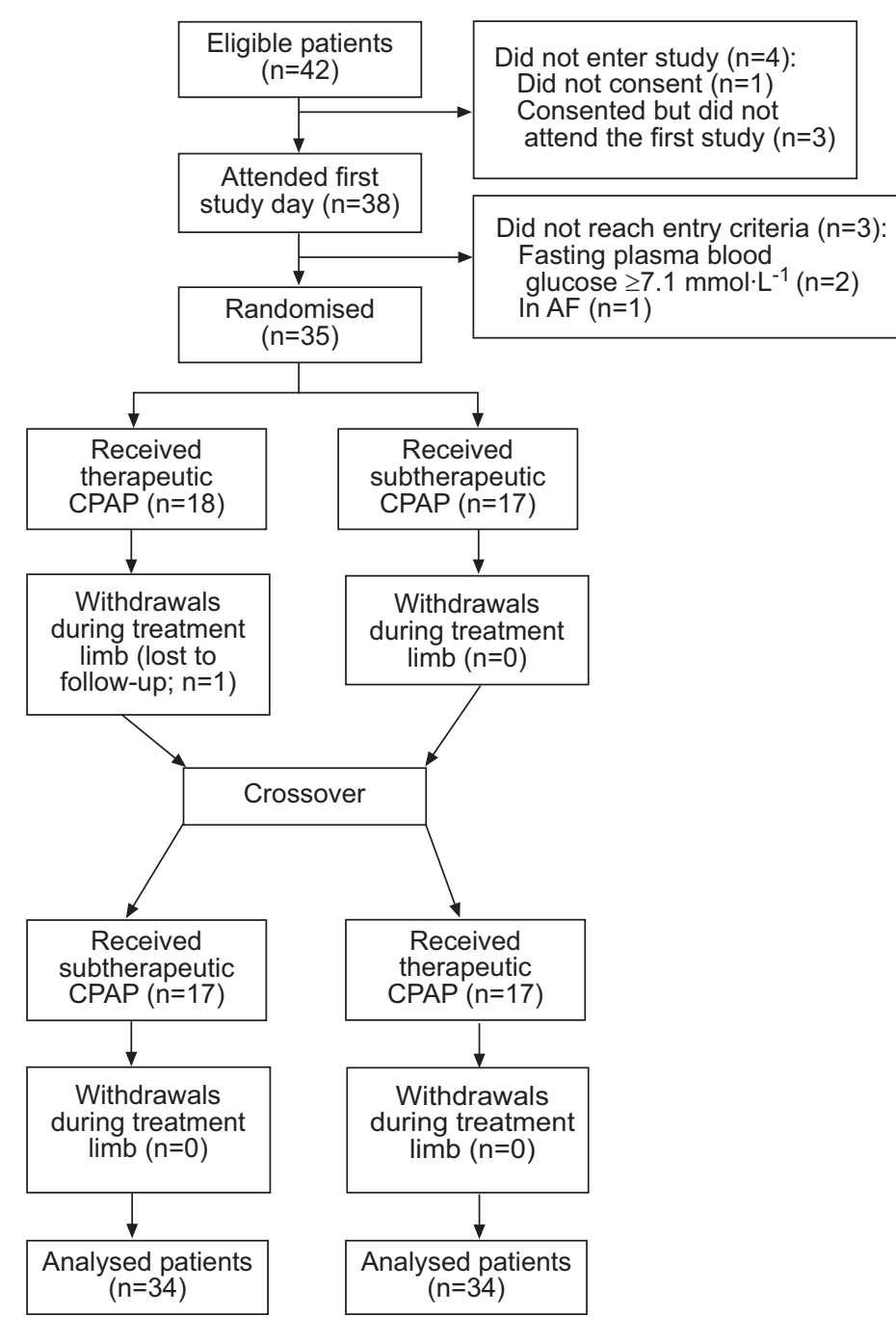

FIGURE 1. Flow chart showing the trial profile. AF: atrial fibrillation; CPAP: continuous positive airways pressure.

Aston, UK) to standardise the effects of respiratory sinus arrhythmia. BRS $\left(\mathrm{ms} \cdot \mathrm{mmHg}^{-1}\right)$ was determined from the spontaneous fluctuations in a 300-s period of stationary blood pressure. ECG data were determined using a transfer function analysis, as the mean modulus between spectral values of blood pressure and heart rate variability in the mid-frequency band $(0.07-0.14 \mathrm{~Hz})$, with a coherence of 0.3 using the CARSPAN programme (Pro GAMMA, Groningen, the Netherlands) [24].

\section{Metabolic variables}

Insulin was quantified using a commercially available insulin assay. Fasting glucose was measured from whole blood using a glucose oxidase-based assay. IR was derived from the fasting glucose and insulin using the homeostasis model assessment (HOMA) calculation, previously validated against the hyperinsulinaemic euglycaemic clamp [25]. Fasting cholesterol, triglyceride and high-density lipoprotein (HDL) cholesterol concentrations were measured with a commercially available immunocolourimetric assay, while low-density lipoprotein cholesterol was derived using the Friedwald equation.
The metabolic syndrome was diagnosed according to the National Cholesterol Education Programme guidelines [10] by the presence of three or more of the following: waist circumference $>102 \mathrm{~cm}$; triglycerides $\geqslant 1.7 \mathrm{mmol} \cdot \mathrm{L}^{-1}$; HDL cholesterol $<1.04 \mathrm{mmol} \cdot \mathrm{L}^{-1}$; systolic and diastolic blood pressure $\geqslant 130$ and $\geqslant 85 \mathrm{mmHg}$, respectively; and fasting glucose $\geqslant 6.1 \mathrm{mmol} \cdot \mathrm{L}^{-1}$.

\section{Data analysis}

The present authors' previous data suggest that $\sim 80 \%$ of untreated male subjects with OSA have the metabolic syndrome. Assuming a minimum clinically significant reduction of $20 \%$ between groups, a sample size of 31 pairs would have $80 \%$ power to detect an absolute difference in proportions of $20 \%$ when the proportion of discordant pairs is expected to be $21 \%$ and the method of analysis is a McNemar's test of equality of paired proportions with a 0.05 two-sided significance level.

As the present study had a crossover design, the appropriate comparison for the effect of treatment was the difference between data at the end of each treatment period, rather than the change from individual baseline values. Data are presented as mean $\pm S D$, unless otherwise stated. Data were analysed on an intention-to-treat (ITT) basis, including all data obtained even if patients were known not to be complying with CPAP therapy. Data were also analysed using the a priori cut-point of $3.5 \mathrm{~h} \cdot$ night $^{-1}$ for reasonable CPAP compliance and for their relationship to baseline variables of interest. Normally distributed continuous random variables were compared using the mean difference, and 95\% confidence interval (CI) for this difference, and paired t-tests. Categorical data were compared using the $95 \%$ CI for the difference in paired proportions and McNemar's Chi-squared test.

\section{RESULTS}

\section{Trial profile}

Four out of the 42 patients eligible to participate withdrew prior to the first study day (fig. 1). Three out of the 38 males who entered the study were excluded before randomisation due to hyperglycaemia $(n=2$; fasting plasma blood glucose $\left.\geqslant 7.1 \mathrm{mmol} \cdot \mathrm{L}^{-1}\right)$ and atrial fibrillation $(n=1)$. Of the 35 randomised patients, one withdrew during the first treatment period (CPAP limb) for personal reasons and was lost to follow-up. A total of 34 patients completed the trial and their baseline data, including the CPAP pressure used in the active limb of the study, are reported in table 1. Patients were predominantly obese and sleepy, with a raised percentage body fat, and most needed $10 \mathrm{cmH}_{2} \mathrm{O} \mathrm{CPAP}$ to abolish their sleep-related breathing abnormalities. There was no significant change in weight, BMI, percentage body fat and fat distribution between the two treatment limbs $(p \geqslant 0.13)$. There was also no evidence of either order or carry-over effect for any outcome variable ( $p \geqslant 0.26$ for all of these comparisons).

\section{Compliance}

Mean (range) time on active CPAP was significantly higher than that on subtherapeutic CPAP (3.9 h. night ${ }^{-1}(0-7.4)$ versus $2.6 \mathrm{~h} \cdot$ night $\left.^{-1}(0-7.5) ; \mathrm{p}<0.01\right)$. Subjects who received CPAP first spent significantly more time on CPAP than the subtherapeutic alternative $(3.9(0-6.2)$ versus $1.9(0-5.5) ; \mathrm{p}<0.01)$. Subjects who received $C P A P$ second used each treatment for a similar length 
of time (4 (0-7.4) for active CPAP versus 3.3 (0-7.5) for subtherapeutic CPAP; $\mathrm{p}=0.22$; data not shown).

\section{ITT analysis}

On an ITT analysis, subjective sleepiness, systolic, diastolic and mean arterial blood pressure were all significantly lower after 6 weeks of CPAP therapy compared with the sham treatment period and the increase in BRS approached significance (table 2, fig. 2). This reflected a reduction of blood pressure on active CPAP rather than any deterioration during the sham treatment period. No significant change was observed in any metabolic variable or in the number of subjects meeting the criteria for the metabolic syndrome between placebo and active CPAP trial periods. The CIs for the change with active CPAP are presented in table 2 for BRS, blood pressure and IR. To explore these relationships further, the present authors related the change in the variable between active and sham treatments to the baseline value of the variable at trial entry. No evidence was found of a relationship between the change in any variable and the initial value of that variable nor was the change in any variable related to the initial BMI or waist circumference.

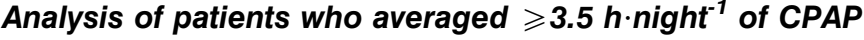 use}

In a subgroup analysis of subjects who averaged $\geqslant 3.5 \mathrm{~h} \cdot$ night $^{-1}$ of CPAP use, subjective sleepiness, systolic, diastolic and mean arterial blood pressure were all significantly reduced following 6 weeks of CPAP therapy (table 3). In this subset the change in BRS now achieved statistical significance in the active treatment $\operatorname{limb}(p<0.04)$.

\section{TABLE 1 Baseline characteristics of the patients studied}

\begin{tabular}{|c|c|}
\hline & Baseline characteristics \\
\hline Subjects $n$ & 34 \\
\hline Age yrs & $49.0 \pm 8.3$ \\
\hline $\mathrm{BMI} \mathbf{k g} \cdot \mathrm{m}^{-2}$ & $36.1 \pm 7.6$ \\
\hline \multicolumn{2}{|l|}{ Obesity } \\
\hline Class I BMI $30-<35$ & $10(30)$ \\
\hline Class $\| \mathrm{BMI} \geqslant 35-<40$ & $8(24)$ \\
\hline Class || $\mid \mathrm{BMI} \geqslant 40$ & $11(32)$ \\
\hline Waist $\mathbf{c m}$ & $117.5 \pm 17.8$ \\
\hline Body fat \% & $39.7 \pm 8.7$ \\
\hline Fat mass kg & $43.1 \pm 14.3$ \\
\hline Neck cm & $48.0(43.0-45.0)$ \\
\hline Hypertension ${ }^{\#}$ & $27(79)$ \\
\hline RDI apnoea $\cdot h^{-1}$ & $39.7 \pm 13.8$ \\
\hline ESS & $13.8 \pm 4.9$ \\
\hline Treatment pressure $\mathrm{cmH}_{2} \mathrm{O}$ & $10.0(8.0-10.0)$ \\
\hline Smoke & $12(35)$ \\
\hline \multicolumn{2}{|l|}{ Alcohol units $\cdot$ week $^{-1}$} \\
\hline $0-4$ & $12(35)$ \\
\hline $4-12$ & $12(35)$ \\
\hline $12-50$ & $10(30)$ \\
\hline
\end{tabular}

Data are presented as mean $\pm \mathrm{SD}, \mathrm{n}(\%)$ or median (interquartile range), unless otherwise stated. BMI: body mass index; RDI: respiratory disturbance index; ESS: Epworth Sleepiness Scale. *: number of patients meeting British Hypertension Society definition of hypertension.

\section{DISCUSSION}

The present study is the first to evaluate the relative impact of CPAP over the first 6 weeks of treatment on both cardiovascular and metabolic outcome variables in OSA patients, most of whom were obese. It was established that changes in each outcome pursue a different time course, with waking blood pressure and BRS changing significantly and consistently after 6 weeks of treatment. In contrast, the metabolic variables, whether fasting glucose, lipids or IR, remained unchanged in the group as a whole irrespective of their compliance with treatment. These data, established in the rigorous setting of a randomised controlled crossover trial, have implications for the understanding of the pathogenesis of the complications associated with OSA and for clinical practice.

Patients included in the study were representative of those attending the present authors' clinical service and were diagnosed using relatively conservative definitions of apnoea and hypopnoea, which are comparable to those used in

\begin{tabular}{|c|c|c|c|c|}
\hline \multirow[t]{2}{*}{ TABLE 2} & \multicolumn{4}{|c|}{$\begin{array}{l}\text { Effects of continuous positive airway pressure } \\
\text { (CPAP) treatment on components of the } \\
\text { metabolic syndrome }\end{array}$} \\
\hline & CPAP & Placebo & Difference $(95 \% \mathrm{Cl})$ & $\mathrm{p}$-value \\
\hline Subjects $n$ & 34 & 34 & & \\
\hline ESS & $9.4 \pm 0.9$ & $12.5 \pm 0.9$ & $-3.1(-4.5--1.7)$ & $<0.01$ \\
\hline \multicolumn{5}{|l|}{ BP mmHg } \\
\hline Systolic & $135.7 \pm 2.0$ & $142.4 \pm 2.4$ & $-6.7(-10.1--3.3)$ & $<0.01$ \\
\hline Diastolic & $86.8 \pm 0.15$ & $91.7 \pm 1.6$ & $-4.9(-8.0--1.8)$ & $<0.01$ \\
\hline Mean arterial & $103.1 \pm 1.5$ & $108.6 \pm 1.7$ & $-5.5(-8.2--2.8)$ & $<0.01$ \\
\hline $\begin{array}{l}\text { BRS } \\
\mathrm{ms} \cdot \mathrm{mmHg}^{-1}\end{array}$ & $5.5 \pm 0.5$ & $4.5 \pm 0.4$ & $1.0(-0.1-2.2)$ & 0.07 \\
\hline $\begin{array}{l}\text { Fasting glucose } \\
\mathrm{mmol} \cdot \mathrm{L}^{-1}\end{array}$ & $4.7 \pm 0.1$ & $4.8 \pm 0.1$ & $-0.1(-0.3-0.03)$ & 0.11 \\
\hline $\begin{array}{l}\text { Fasting insulin } \\
\mathrm{pmol} \cdot \mathrm{L}^{-1}\end{array}$ & $15.5 \pm 1.6$ & $18.1 \pm 2.0$ & $-2.6(-5.9-0.8)$ & 0.13 \\
\hline HOMA IR & $3.3 \pm 0.4$ & $3.9 \pm 0.5$ & $-0.6(-1.3-0.1)$ & 0.08 \\
\hline $\begin{array}{c}\text { Cholesterol } \\
\mathrm{mmol} \cdot \mathrm{L}^{-1}\end{array}$ & $5.5 \pm 0.1$ & $5.7 \pm 0.1$ & $-0.2(-0.5-0.1)$ & 0.29 \\
\hline $\begin{array}{c}\text { Triglycerides } \\
\mathrm{mmol} \cdot \mathrm{L}^{-1}\end{array}$ & $1.8 \pm 0.2$ & $1.9 \pm 0.2$ & $-0.1(-0.5-0.2)$ & 0.31 \\
\hline $\mathrm{HDL} \mathrm{mmol} \cdot \mathrm{L}^{-1}$ & $1.1 \pm 0.1$ & $1.1 \pm 0.1$ & $0.0(-0.1-0.04)$ & 0.30 \\
\hline LDL $\mathrm{mmol} \cdot \mathrm{L}^{-1}$ & $3.6 \pm 0.1$ & $3.7 \pm 0.1$ & $-0.1(-0.2-0.2)$ & 0.83 \\
\hline $\begin{array}{l}\text { Cholesterol } \\
\text { HDL }\end{array}$ & $5.2 \pm 0.2$ & $5.3 \pm 0.2$ & $-0.1(-0.3-0.2)$ & 0.73 \\
\hline $\begin{array}{l}\text { Metabolic } \\
\text { syndrome }{ }^{\#}\end{array}$ & $27(79)$ & $29(85)$ & $-0.08-0.20$ & 0.63 \\
\hline
\end{tabular}

Data are presented as mean \pm SEM or $n(\%)$, unless otherwise stated. Normally distributed continuous random variables were compared using the mean difference and $95 \%$ confidence interval $(\mathrm{Cl})$ of this difference. Categorical data were compared using the $95 \% \mathrm{Cl}$ for the difference in paired proportions. Paired t-tests were performed on normally distributed continuous random variables and McNemar's Chi-squared tests on categorical data. ESS: Epworth Sleepiness Scale; BP: blood pressure; BRS: baroreceptor sensitivity; HOMA: homeostasis model assessment; IR: insulin resistance; HDL: high-density lipoprotein; LDL: low-density lipoprotein. \#: diagnosed according to the National Cholesterol Education Programme criteria. 

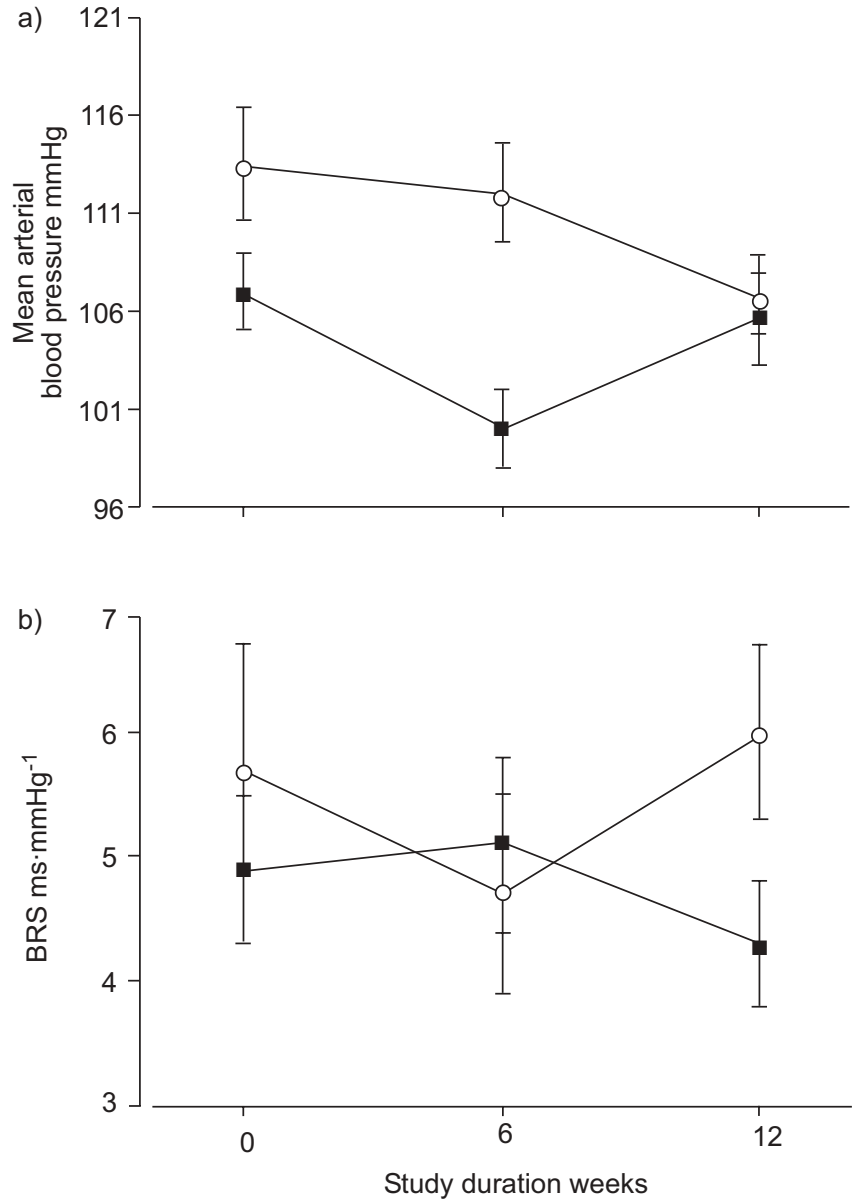

FIGURE 2. Effect of continuous positive airway pressure (CPAP) on a) mean arterial blood pressure and b) baroreceptor sensitivity (BRS). $\bigcirc$ : baseline-placeboCPAP; $\mathbf{n}$ : baseline-CPAP-placebo. The whiskers represent SEM.

patients studied without polysomnographically confirmed OSA [14, 15]. Trial patients were selected to be free from medication and to be either normotensive or unwilling to use treatment at the levels of blood pressure included at recruitment. The change in waking blood pressure, measured under standardised conditions to minimise pressor factors, was both statistically and clinically significant. As shown in figure 2, there was a fall in blood pressure in those receiving active therapy first, while blood pressure remained constant in those patients where placebo CPAP was administered second, producing a reverse pattern. These differences in waking blood pressure after CPAP treatment were similar to those identified in the present study when comparing a different group of OSA patients studied before therapy began with a group of age and weight-matched controls [12]. In these studies it was found that, using the same methodology, the standardised measurement of waking blood pressure identified important differences between groups and treatments. This reduction in blood pressure is greater than that previously reported on CPAP when measuring blood pressure at hourly intervals throughout the daytime $[15,16]$. This is possibly due to the fact that blood pressure was estimated at the same time of day in each patient.? Data from large prospective studies suggest that a reduction in blood pressure of $5.5 \mathrm{mmHg}$, as

\begin{tabular}{|c|c|c|c|c|}
\hline \multirow[t]{2}{*}{ TABLE 3} & \multicolumn{4}{|c|}{$\begin{array}{l}\text { Effects of continuous positive airways pressure } \\
\text { (CPAP) treatment on components of the } \\
\text { metabolic syndrome in subjects who } \\
\text { demonstrated adequate compliance } \\
\left(\geqslant 3.5 \mathrm{~h} \cdot \text { night }^{-1}\right)\end{array}$} \\
\hline & CPAP & Placebo & $\begin{array}{l}\text { Difference } \\
(95 \% \mathrm{Cl})\end{array}$ & p-value \\
\hline Subjects $\mathrm{n}$ & 23 & 23 & & \\
\hline ESS & $9.2 \pm 1.2$ & $13.1 \pm 1.0$ & $-3.9(-5.7--2.1)$ & $<0.01$ \\
\hline \multicolumn{5}{|l|}{ BP $\mathrm{mmHg}$} \\
\hline Systolic & $133.7 \pm 2.5$ & $142.2 \pm 2.8$ & $-8.5(-12.7--4.3)$ & $<0.01$ \\
\hline Diastolic & $86.6 \pm 1.9$ & $93.3 \pm 1.7$ & $-6.7(-10.9--2.5)$ & $<0.01$ \\
\hline Mean arterial & $102.3 \pm 1.9$ & $109.6 \pm 2.0$ & $-7.3(-10.8--3.8)$ & $<0.01$ \\
\hline BRS $\mathrm{ms} \cdot \mathrm{mmHg}^{-1}$ & $6.1 \pm 0.6$ & $4.7 \pm 0.3$ & $1.4(0.1-2.7)$ & $<0.04$ \\
\hline $\begin{array}{l}\text { Fasting glucose } \\
\mathrm{mmol} \cdot \mathrm{L}^{-1}\end{array}$ & $4.6 \pm 0.1$ & $4.7 \pm 0.1$ & $-0.1(-0.3-0.1)$ & 0.31 \\
\hline $\begin{array}{l}\text { Fasting insulin } \\
\text { pmol } \cdot \mathrm{L}^{-1}\end{array}$ & $13.8 \pm 1.6$ & $15.5 \pm 2.2$ & $-1.7(-4.8-1.4)$ & 0.29 \\
\hline HOMA IR & $2.8 \pm 0.3$ & $3.2 \pm 0.5$ & $-0.4(-1.1-0.3)$ & 0.22 \\
\hline $\begin{array}{c}\text { Cholesterol } \\
\mathrm{mmol} \cdot \mathrm{L}^{-1}\end{array}$ & $5.4 \pm 0.2$ & $5.7 \pm 0.2$ & $-0.3(-0.6-0.02)$ & 0.07 \\
\hline $\begin{array}{c}\text { Triglycerides } \\
\mathrm{mmol} \cdot \mathrm{L}^{-1}\end{array}$ & $1.7 \pm 0.2$ & $1.9 \pm 0.3$ & $-0.2(-0.7-0.3)$ & 0.33 \\
\hline $\mathrm{HDL} \mathrm{mmol} \cdot \mathrm{L}^{-1}$ & $1.1 \pm 0.1$ & $1.2 \pm 0.1$ & $-0.1(-0.2-0.03)$ & 0.15 \\
\hline $\mathrm{LDL} \mathrm{mmol} \cdot \mathrm{L}^{-1}$ & $3.5 \pm 0.1$ & $3.7 \pm 0.2$ & $-0.2(-0.5-0.1)$ & 0.66 \\
\hline Cholesterol HDL & $5.0 \pm 0.2$ & $5.1 \pm 0.3$ & $-0.1(-0.4-0.2)$ & 0.62 \\
\hline $\begin{array}{l}\text { Metabolic } \\
\text { syndrome }\end{array}$ & $16(70)$ & $19(83)$ & $-0.04-0.30$ & 0.25 \\
\hline
\end{tabular}

Data are presented as mean \pm SEM or $n(\%)$, unless otherwise stated. Normally distributed continuous random variables were compared using the mean difference and $95 \%$ confidence interval $(\mathrm{Cl})$ of this difference. Categorical data were compared using the $95 \% \mathrm{Cl}$ for the difference in paired proportions. Paired t-tests were performed on normally distributed continuous random variables and McNemar's Chi-squared tests on categorical data. ESS: Epworth Sleepiness Scale; BP: blood pressure; BRS: baroreceptor sensitivity; HOMA: homeostasis model assessment; IR: insulin resistance; HDL: high-density lipoprotein; LDL: low-density lipoprotein. "*: diagnosed according to the National Cholesterol Education Programme criteria.

seen in the present study, would be associated with a stroke risk reduction of $\sim 30 \%$ and coronary heart disease event risk reduction of $20 \%$ [26]. Thus the changes observed provide a rationale for the reduced incidence of cardiovascular disease previously reported in effectively treated OSA patients in a 7-yr follow-up study [27]. This improvement in blood pressure in the present sleepy apnoeic patients contrasts with the lack of response to CPAP in patients without excessive daytime sleepiness, a finding recently confirmed in a randomised controlled clinical trial which used the same sham methodology employed in the present study [28]. Whether metabolic variables were altered in these less common nonsleepy OSA patients has not been reported but would usefully complement the present data were it to become available.

The change in BRS did not reach statistical significance in the ITT population, reflecting the greater measurement variability of this test compared with standardised blood pressure 
recording and possibly a smaller impact of CPAP on 24-h blood pressure, as suggested by the ambulatory blood pressure data $[15,16]$. The present data also suggest that reduction in BRS is not the only mechanism determining morning blood pressure change in OSA patients after 6 weeks of treatment and are in keeping with recent reports that obesity and OSA have independent effects on adrenergic activation [29]. However, the changes in blood pressure seen in those patients who complied with treatment were larger and the increase in BRS reached statistical significance in this group. Depressed BRS is known to be an independent marker of poor prognosis after an acute myocardial infarction [30]. Although the changes observed before treatment were relatively modest, their correction may translate to an important additional protective benefit if maintained over a longer period.

In contrast, no significant changes were observed in fasting glucose or lipids over the 6 weeks of CPAP treatment and hence there was no significant change in the number of patients classified as having the metabolic syndrome. This is disappointing since differences in HDL cholesterol were identified as being an important factor distinguishing cases and controls in the present cross-sectional comparison. Recently data obtained in the course of two other randomised parallel group trials of CPAP therapy found a trend to reduction in nonfasting total cholesterol after 1 month of treatment, which became significant when patients were reclassified according to their use of therapeutic CPAP [31]. At the same time, a large population-based study found a small but significant improvement in HDL cholesterol after 6 months of CPAP therapy most evident in those with abnormal initial values [32]. Replicating this effect in a randomised controlled trial is likely to be extremely difficult.

The evidence about the role of CPAP in reducing IR in OSA is conflicting [33, 34], although the present study is the first randomised controlled trial data to report using this end-point. An effect of CPAP treatment on IR has been reported in uncontrolled studies of type-2 diabetics with OSA [35] and in OSA in patients with a mean lower BMI [17]. There is always a risk of regression to the mean in data like these, although the randomised blinded treatment allocation used lessens the impact of this. The observations by IP et al. [7], who used insulin clamping to determine insulin sensitivity, are particularly relevant to the present findings. The magnitude of response to CPAP in this uncontrolled interventional study was inversely related to the initial BMI. The patients included in the present study were more obese than those in the study by BROOKS et al. [35] and no relationship was observed between any measure of body fat and the subsequent IR assessed indirectly. Indeed, calculation of the BMI of the subgroup studied after 3 months of CPAP with a BMI $>30$ in the data reported by BROOKS et al. [35] suggests it is similar to the data in the present trial and the changes in insulin sensitivity at 3 months are largely due to improvements in those individuals with a BMI close to $30 \mathrm{~kg} \cdot \mathrm{m}^{-2}$. This suggests that there may be a threshold level of obesity where excess body fat is the principal determinant of insulin sensitivity irrespective of the presence of sleep apnoea or its severity. This would be compatible with the large data set provided by IP et al. [7], where obesity was the major determinant of IR measured according to the HOMA method with a proportionately smaller effect from OSA. Clearly, longer periods of study will be required to investigate whether changes in IR occur in obese subjects and to determine whether the presence of clinical diabetes changes the responsiveness to therapy. Obesity rather than OSA has been shown to drive other relationships that were initially thought to be a feature of OSA, such as raised serum C-reactive protein levels [36]. However, the present data do demonstrate that important changes in cardiovascular variables occur relatively rapidly and independently of changes in metabolic outcomes or baseline conditions.

Compliance with CPAP is a potentially important confounding variable. As sham CPAP was used rather than a placebo tablet, machine run time was accepted as the surrogate measure of compliance instead of mask pressure. Previous studies have reported a good relationship between these measures and the fall in ESS on active treatment was significantly greater than that on placebo, which may explain the better compliance with active rather than sham therapy in those individuals who received active therapy first. The better compliance with placebo therapy during the second treatment limb may reflect a carry-over effect of successful earlier treatment. However, no other carry-over or order effects were observed. Although individuals who use CPAP for $>3.5 \mathrm{~h} \cdot$ night $^{-1}$, which was close to the median CPAP use of $4.2 \mathrm{~h}$, showed greater changes in blood pressure and BRS, still there was no significant difference in the metabolic variables or the number and the criteria for the metabolic syndrome. Whether longer periods of compliant therapy will be more successful cannot be addressed in the present study.

In summary, in the present randomised blinded crossover trial in obese Caucasians symptomatic from OSA, significant changes have been confirmed in waking arterial blood pressure within 6 weeks of commencement of continuous positive airway pressure treatment and these are greatest in patients who comply best with continuous positive airway pressure therapy. Baroreceptor sensitivity also improves but, in the present group of relatively obese symptomatic patients, no evidence was found of an improvement in insulin resistance or change in serum lipids over the treatment period and hence no change in the number of individuals classified as having the metabolic syndrome. These data suggest that, while a reduction in sympathetic activation is likely when obstructive sleep apnoea is treated [37] and helps explain the altered cardiovascular responses, this is not sufficient to modify the degree of insulin resistance in the patients over this time frame and other mechanisms predominate to drive insulin resistance in these circumstances. The present results emphasise the need to offer multiple modalities of treatment to obese obstructive sleep apnoea patients if their cardiovascular risk profile is to be successfully modified.

\section{ACKNOWLEDGEMENTS}

The authors would like to thank V. Daly, T. McKown, P. Parry and J. Dowsett for randomising patients to CPAP and the subtherapeutic control, setting-up and allocating patients with their machines and dealing with compliance issues. Finally, the authors would like to thank M. Pearce and D. Ladanowski for logistical support, and P. Thompson for providing support and advice on assay techniques. 


\section{REFERENCES}

1 Young T, Palta M, Dempsey J, Skatrud J, Weber S, Badr S. The occurrence of sleep-disordered breathing among middle-aged adults. $N$ Engl J Med 1993; 328: 1230-1235.

2 Douglas NJ, Polo O. Pathogenesis of obstructive sleep apnoea/hypopnoea syndrome. Lancet 1994; 344: 653-655.

3 Lattimore JD, Celermajer DS, Wilcox I. Obstructive sleep apnea and cardiovascular disease. J Am Coll Cardiol 2003; 41: 1429-1437.

4 Young T, Peppard P, Palta M, et al. Population-based study of sleep-disordered breathing as a risk factor for hypertension. Arch Intern Med 1997; 157: 1746-1752.

5 Nieto FJ, Young TB, Lind BK, et al. Association of sleepdisordered breathing, sleep apnea, and hypertension in a large community-based study. Sleep Heart Health Study. JAMA 2000; 283: 1829-1836.

6 Stoohs RA, Facchini F, Guilleminault C. Insulin resistance and sleep-disordered breathing in healthy humans. Am J Respir Crit Care Med 1996; 154: 170-174.

7 Ip MS, Lam B, Ng MM, Lam WK, Tsang KW, Lam KS. Obstructive sleep apnea is independently associated with insulin resistance. Am J Respir Crit Care Med 2002; 165: 670-676.

8 Punjabi NM, Sorkin JD, Katzel LI, Goldberg AP, Schwartz AR, Smith PL. Sleep-disordered breathing and insulin resistance in middle-aged and overweight men. Am J Respir Crit Care Med 2002; 165: 677-682.

9 Punjabi NM, Shahar E, Redline S, et al. Sleep-disordered breathing, glucose intolerance, and insulin resistance: the Sleep Heart Health Study. Am J Epidemiol 2004; 160: 521-530.

10 Meslier N, Gagnadoux F, Giraud P, et al. Impaired glucoseinsulin metabolism in males with obstructive sleep apnoea syndrome. Eur Respir J 2003; 22: 156-160.

11 Expert Panel on Detection, Evaluation, and Treatment of High Blood Cholesterol in Adults, Executive Summary of The Third Report of The National Cholesterol Education Program (NCEP) Expert Panel on Detection, Evaluation, and Treatment of High Blood Cholesterol in Adults (Adult Treatment Panel III). JAMA 2001; 285: 2486-2497.

12 Coughlin SR, Mawdsley L, Mugarza JA, Calverley PM, Wilding JP. Obstructive sleep apnoea is independently associated with an increased prevalence of metabolic syndrome. Eur Heart J 2004; 25: 735-741.

13 Engleman HM, Martin SE, Deary IJ, Douglas NJ. Effect of continuous positive airway pressure treatment on daytime function in sleep apnoea/hypopnoea syndrome. Lancet 1994; 343: 572-575.

14 Jenkinson C, Davies RJ, Mullins R, Stradling JR. Comparison of therapeutic and subtherapeutic nasal continuous positive airway pressure for obstructive sleep apnoea: a randomised prospective parallel trial. Lancet 1999; 353: 2100-2105.

15 Pepperell JC, Ramdassingh-Dow S, Crosthwaite N, et al. Ambulatory blood pressure after therapeutic and subtherapeutic nasal continuous positive airway pressure for obstructive sleep apnoea: a randomised parallel trial. Lancet 2002; 359: 204-210.

16 Faccenda JF, Mackay TW, Boon NA, Douglas NJ. Randomized placebo-controlled trial of continuous positive airway pressure on blood pressure in the sleep apnoea-hypopnea syndrome. Am J Respir Crit Care Med 2001; 163: 344-348.
17 Harsch IA, Schahin SP, Radespiel-Troger $\mathrm{M}$, et al. Continuous positive airway pressure treatment rapidly improves insulin sensitivity in patients with obstructive sleep apnea syndrome. Am J Respir Crit Care Med 2004; 169: 156-162.

18 Johns MW. Daytime sleepiness, snoring, and obstructive sleep apnea. The Epworth Sleepiness Scale. Chest 1993; 103: 30-36.

19 Sleep-related breathing disorders in adults, recommendations for syndrome definition and measurement techniques in clinical research. The Report of an American Academy of Sleep Medicine Task Force. Sleep 1999; 22: 667-689.

20 Teschler H, Berthon-Jones M, Thompson AB, Henkel A, Henry J, Konietzko N. Automated continuous positive airway pressure titration for obstructive sleep apnea syndrome. Am J Respir Crit Care Med 1996; 154: 734-740.

21 Farre R, Hernandez L, Montserrat JM, Rotger M, Ballester E, Navajas D. Sham continuous positive airway pressure for placebo-controlled studies in sleep apnoea. Lancet 1999; 353: 1154.

22 Engleman HM, Martin SE, Douglas NJ. Compliance with CPAP therapy in patients with the sleep apnoea/hypopnoea syndrome. Thorax 1994; 49: 263-266.

23 Jebb SA, Cole TJ, Doman D, Murgatroyd PR, Prentice AM. Evaluation of the novel Tanita body-fat analyser to measure body composition by comparison with a fourcompartment model. Br J Nutr 2000; 83: 115-122.

24 Saul JP, Berger RD, Albrecht P, Stein SP, Chen MH, Cohen RJ. Transfer function analysis of the circulation: unique insights into cardiovascular regulation. Am J Physiol 1991; 261: H1231-H1245.

25 Matthews DR, Hosker JP, Rudenski AS, Naylor BA, Treacher DF, Turner RC. Homeostasis model assessment: insulin resistance and beta-cell function from fasting plasma glucose and insulin concentrations in man. Diabetologia 1985; 28: 412-419.

26 MacMahon S, Peto R, Cutler J, et al. Blood pressure, stroke, and coronary heart disease. Part 1, prolonged differences in blood pressure: prospective observational studies corrected for the regression dilution bias. Lancet 1990; 335: 765-774.

27 Peker Y, Hedner J, Norum J, Kraiczi H, Carlson J. Increased incidence of cardiovascular disease in middle-aged men with obstructive sleep apnea: a 7-year follow-up. Am J Respir Crit Care Med 2002; 166: 159-165.

28 Robinson GV, Smith DM, Langford BA, Davies RJ, Stradling JR. Continuous positive airway pressure does not reduce blood pressure in nonsleepy hypertensive OSA patients. Eur Respir J 2006; 27: 1229-1235.

29 Grassi G, Facchini A, Trevano F, et al. Obstructive sleep apnea-dependent and -independent adrenergic activation in obesity. Hypertension 2005; 46: 321-325.

30 La Rovere MT, Bigger JT Jr, Marcus FI, Mortara A, Schwartz PJ. Baroreflex sensitivity and heart-rate variability in prediction of total cardiac mortality after myocardial infarction. ATRAMI (Autonomic Tone and Reflexes After Myocardial Infarction) Investigators. Lancet 1998; 351: 478-484.

31 Robinson GV, Pepperell JC, Segal HC, Davies RJ Stradling JR. Circulating cardiovascular risk factors in 
obstructive sleep apnoea: data from randomised controlled trials. Thorax 2004; 59: 777-782.

32 Borgel J, Sanner BM, Bittlinsky A, et al. Obstructive sleep apnoea and its therapy influence high-density lipoprotein cholesterol serum levels. Eur Respir J 2006; 27: 121-127.

33 Punjabi NM, Ahmed MM, Polotsky VY, Beamer BA, O'Donnell CP. Sleep-disordered breathing, glucose intolerance, and insulin resistance. Respir Physiol Neurobiol 2003; 136: 167-178.

34 Tauman R, O'Brien L, Ivanenko A, Gozal D. Obesity rather than severity of sleep-disordered breathing as the major determinant of insulin resistance and altered lipidemia in snoring children. Pediatrics 2005; 116: e66-e73.
35 Brooks B, Cistulli PA, Borkman M, et al. Obstructive sleep apnoea in obese noninsulin-dependent diabetic patients: effect of continuous positive airway pressure treatment on insulin responsiveness. J Clin Endocrinol Metab 1994; 79: 1681-1685.

36 Barcelo A, Barbe F, Llompart E, et al. Effects of obesity on $\mathrm{C}$-reactive protein level and metabolic disturbances in male patients with obstructive sleep apnea. Am J Med 2004; 117: 118-121.

37 Hedner J, Darpo B, Ejnell H, Carlson J, Caidahl K. Reduction in sympathetic activity after long-term CPAP treatment in sleep apnoea: cardiovascular implications. Eur Respir J 1995; 8: 222-229. 